\title{
Effect of PEG Induced Drought Stress on Seed Germination and Seedling Characters of Maize (Zea mays L.) Genotypes
}

\author{
C. Partheeban $^{1}$, C.N. Chandrasekhar ${ }^{1}$, P. Jeyakumar ${ }^{1}$, R. Ravikesavan ${ }^{2}$ and R. Gnanam ${ }^{4}$ \\ ${ }^{1}$ Department of Crop Physiology, Tamil Nadu Agricultural University, Coimbatore, India \\ ${ }^{2}$ Department of Millets, Centre for Plant Breeding and Genetics, Tamil Nadu Agricultural \\ University, Coimbatore, India \\ ${ }^{4}$ Department of Plant Biotechnology, Centre for Plant Molecular Biology, Tamil Nadu \\ Agricultural University, Coimbatore, India \\ *Corresponding author
}

\author{
A B S T R A C T
}

Keywords

Maize,

Polyethyleneglycol6000 (PEG-6000),

Drought stress, Germination, Root.

Article Info

Accepted:

12 April 2017

Available Online:

10 May 2017
Drought stress is one of the most important environmental issues that reduce growth, development and yield of the plants. Developing maize cultivars that can perform well in drought and other abiotic stress is an important goal throughout the world. Germination is one of the main growth stages for seedling establishment, and success in this stage is dependent on moisture availability in the soil. A laboratory experiment was conducted to evaluate the germination characteristics of four maize genotypes under four levels of osmotic stress $(0,-2,-4$ and -6 bar). Polyethylene glycol (PEG) 6000 was used as an osmoticum. This investigation was performed as factorial experiment under Completely Randomized Design (CRD) with three replications. Germination and early growth were affected by drought stress. Results showed that water stress treatments significantly $(\mathrm{P}<0.05)$ influenced the Emergence Percentage (EP) (\%), Promptness Index (PI) (\%), Germination Stress Tolerance Index (GSTI) (\%), Plant Height Stress Index (PHSI) (\%), Root Length Stress Index (RLSI) (\%), Primary root length, Number of seminal root, Seminal root length and seed vigour (\%) of different cultivars of maize i.e., VIM455, VIM147, VIM213 and VIM396. The result of this experiment indicated that the two maize genotypesVIM147 and VIM396exhibited tolerance against drought stress compared to VIM455 and VIM213. The variation among genotypes for germination stress tolerance index (GSI) and Root length stress index (RLSI) was found to be a reliable indicator to screen the drought tolerant genotypes at germination and seedling stage in maize.

\section{Introduction}

Abiotic stress is the primary cause of crop loss worldwide, reducing average yields for most major crop plants by more than $50 \%$ (Boyer, 1982). Among the abiotic stresses, drought stress is one of the most important environmental factors that reduce growth, development and production of plants. It can be said that it is one of the most devastating environmental stresses (Xiong et al., 2006). Maize is an important cereal crop grown all over the world (Farhad et al., 2009). Also, it is a staple food and commercial crop (Trida $e t$ al., 2006) which is sensitive to drought. Maize is produced on nearly 100 million hectares in developing countries, with almost 70 per cent of the total maize production in 
the developing world coming from low and lower middle income countries (FAOSTAT, 2014). By 2050, demand for maize will double in the developing world, and maize is predicted to become the crop with the greatest production globally, and in the developing world by 2025 (Rosegrant et al., 2008).

Water stress affects almost every developmental stage of the plant. However, damaging effects of this stress was more noted when it coincided with various growth stages such as germination; seedling shoot length, root length and flowering (Rauf, 2008; Khayatnezhad et al., 2010). Water stress not only affects seed germination but also increases mean germination time in maize plants (Willanborb et al., 2004). The adverse effect of water shortage on germination and seedling growth has been well reported in different crops (Mostafavi et al., 2011; Khodarahmpour, 2011).The polyethylene glycol (PEG)-induced inhibition of germination has been attributed to osmotic stress (Dodd and Donovan, 1999; Sidari et al., 2008).

For the development of elite lines having drought tolerance, the existence of variability among the available maize germplasm is a key to success for the maize breeders. This current study was planned to explore the variation and determine the target traits conferring drought tolerance in maize. An artificially created water-stress environment is used to provide the opportunity in selecting superior genotypes out of a large population. The solutions of high molecular weight polyethylene glycol are often used to control water potential in seed germination studies (Hardegree and Emmerich, 1990). The aim of the present study was to investigate the effects of osmotic stress generated by different concentration of PEG on emergence characteristics and seedling growth characters of maize genotypes.

\section{Materials and Methods}

The present research work was carried out at the Department of Crop Physiology, Tamil Nadu Agricultural University, Coimbatore, Tamil Nadu. Four maize genotypes (VIM455, VIM147, VIM213 and VIM396) were used to study the effect of drought stress by using PEG-6000 on germination and early seedling growth characters. The study was performed in petriplates having filter paper. The seeds were selected for size homogeneity, surface sterilized for $5 \mathrm{~min}$ in $1 \%(\mathrm{v} / \mathrm{v})$ sodium hypochlorite and then rinsed twice in distilled water. Ten seeds of each genotype was placed in the petridishes with corresponding PEG concentration $(0,-2,-4$ and -4 bars $)$ and kept in an incubator (40\% relative humidity) at $25^{\circ} \mathrm{C}$. Respective PEG solution was applied to every petriplate on daily basis after draining out the previously applied solution. Number of seeds germinated was manually counted on each day up to 7 days and the seed germination characters was considered based on the emergence of radicle and plumule $(2 \mathrm{~mm})$. After seven days, emergence percentage and seedling vigour index was measured by following the protocol of International Seed Testing Association (ISTA, 1996). The Promptness Index (PI) and Germination Stress Tolerance Index (GSI) were calculated using the following formulae given by Ashraf et al., (1990).

By the end of the $7^{\text {th }}$ day, Plant Height Stress Index (PHSI)(\%), Root Length Stress Index (RLSI) (\%), Primary Root Length(PRL) (cm), Number of Seminal Root(NSL), Seminal Root Length $(\mathrm{SRL})(\mathrm{cm})$ and seed vigour (\%)were also measured (Ellis and Robert, 1981).

\section{1. $\mathrm{EP}(\%)=(\mathrm{NGS} / \mathrm{TNS}) \times 100$}

Where, EP is Emergence percentage, NGS is the number of germinated seeds and TNS is 
the total number of viable seeds taken for the experiment (Scott et al., 1984).

2. PI $(\%)=$ nd2 $(1.00)+\mathrm{nd} 4(0.75)+\mathrm{nd} 6(0.5)$ $+\mathrm{nd} 8(0.25)$

Where, PI is promptness index, nd is the number of seeds germinated on the day of observation (George, 1967)

3. GSTI $(\%)=[\mathrm{PI}$ of stressed seeds / PI control seeds] x 100

Where, GSTI is Germination Stress Tolerance Index

4. PHSI $(\%)=($ Plant height of stressed plant $/$ Plant height of control plants) x 100

Where, PHSI is Plant height stress index

5. RLSI $(\%)=($ Root length stressed plant $/$ Root length of control plants) x 100

Where, RLSI is Root length stress index (RLSI)

6. Seed vigour $(\mathrm{SV})=$ germination percentage $\times$ seedling length

The data collected were subjected to analysis of variance technique (Steel et al., 1997) using Minitab7 and SPSS V.20 statistical software and numerical taxonomic techniques following the procedure of principal component analysis (Sneath and Sokal, 1973).

\section{Results and Discussion}

The results of this study reveal that different concentrations of PEG-6000such as -2 bars, 4 bars and -6 bars along with the control had significant $(\mathrm{P} \leq 0.01)$ effect on the germination of maize genotypes (VIM455, VIM147, VIM213 and VIM396).Analysis of variance and mean comparison showed that there were significant differences between drought stress levels and genotypes (Table 1 and Fig. 1).

The emergence percentage was found nonsignificant for the maize genotypes under control. PEG applied at- 6 bars showed that the two maize genotypesVIM147 (20.10\%) and VIM396 (10\%) performed better and showed tolerance against artificially induced water stress (Table 4). Emergence percentage of all maize genotypes was adversely affected due to the application of different levels (-2, 4 and -6 bar) of PEG. The results show that there was a decrease in germination percentage of all the four maize with increase in the stress levels (Table 4). The control seedlings, recorded a mean emergence percentage of 100 while stress induced seedlings depicted an EP of only 7.71 (Table $2)$. The results were in agreement with the reports of Khayatnezhad et al., (2010), Khodarahmpour (2011) and Mostafavi et al., (2011). Ahmad et al., (2009) also reported that drought stress has an inhibitory effect on sunflower seed germination. According to Ayaz et al., (2001), decrease in seed germination under stress conditions is due to some metabolic disorders. Increasing drought stress levels caused delay in seedling emergence as a result of reduced cell division and plant growth metabolism.

Based on the data, promptness index was calculated to identify the sensitive and tolerant maize genotypes. Maize genotypes VIM147 (1.59) and VIM396 (1.05) gave higher promptness index and performed better than VIM455 and VIM233 when stress was induced at -6 bars (Table 4). Higher PI showed that the maize genotypes VIM147 and VIM396 are drought tolerant. The water stress induced by PEG-6000 showed that the Germination Stress Tolerance Index (GSTI) decreased with increasing concentration of stress levels. The GSTI values ranged from 
$15.88 \%$ to $2.48 \%$ at -6 bars indicating more pronounced differences among genotypes compared to control (Table 4 and Fig. 1). GSTI was highest in VIM147 (72.61) and lowest in VIM213 (55.34) (Table 3). At -2 bars PEG, the highest GSTI (78.36\%) value was recorded in maize genotype VIM147, while the lowest $(69.29 \%)$ was recorded in VIM213 (Table 2). These results were similar to those of Ahmad et al., (2009) who reported that PEG induced water stress at germination and seedling growth stages reduced the GSTI in six sunflower hybrids/breeding lines. The GSTI was used to interpret differences in the rate of germination due to osmotic stress (Bouslama and Schapaugh, 1984). Higher value of the GSI showed a high rate of germination which was inversely related to moisture stress.

The physiological indices such as plant height stress index (PHSI), root length stress index (RLSI), primary root length (PRL), Seminal root length (SRL) and number of seminal root were calculated from all maize genotypes. The root length provides an important clue to the response of plants to drought stress. A significant reduction in root and shoot length of all genotypes of maize was observed because of drought stress. Among the genotypes, VIM147 had the highest Plant height stress index (PHSI) (\%), Root length stress index (RLSI) (\%), Primary root length, Number of seminal root and Seminal root length.The highest mean PHSI and RLSI value was recorded in maize genotype VIM147 $(71.44 \%, 67.17 \%)$, whereas the lowest $(37.43 \%, 39.42 \%)$ was recorded in the maize genotype VIM213 (Table 3). Under normal conditions, highest primary root length, seminal root and number of seminal root (Table 4) were shown by VIM455 (21.92, 11.3 and 5.06). There were no significant differences observed in seminal root number under control conditions. Under drought condition at $-2,-4$ and -6 bars, the best performance regarding primary root length, seminal root and number of seminal root was shown by VIM147 followed by VIM396.

Nejad (2011) reported that major parameters in drought conditions such as root length, number, decreased in mild water stress $(50 \%$ of the amount of irrigation treatments). Root length increased under conditions of severe water stress. The most severe level in reducing shoot length and root length was -6 bar of PEG. There are several reports in the literature for potential drought resistance traits like extensive viable root system that could explore deeper soil layers for water (Mirza, 1956; Bocev, 1963). Maize plants with more roots at seedling stage subsequently developed stronger root architecture system, produce more green matter and had higher values for most characters determining seed yield (Bocev, 1963).

Multivariate scoring was carried out using Principle Components Analysis (Fig. 2) using replicated Emergence percentage (EP) (\%), Promptness Index (PI)(\%), Germination stress tolerance index (GSTI)(\%), Plant height stress index (PHSI)(\%), Root length stress index (RLSI) (\%), Primary root length, Number of seminal root, Seminal root length and seed vigour (\%).Principal Component Analysis (PCA) is the most frequently used multivariate method. The four maize genotypes represent two distinct patterns or groups with differing responses to water stress that could be advanced for further testing to drought tolerance. Positive, negative and highly significant correlation was observed between the pairs of traits (Fig. 3). These are positively correlated that if one increases the other will also increase and vice versa. These results are in agreement with the results of Khan et al., (2004a). 
Table.1 Analysis of variance on mean of squares of measured traits in maize genotypes under drought stress

\begin{tabular}{|c|c|c|c|c|c|c|c|c|c|c|}
\hline S.O.V & Df & EP & PI & GSTI & PHSI & RLSI & PR & SR & NSR & SV \\
\hline G & 3 & 1308.37 & 11.01 & 1101.40 & 3502.85 & 3173.64 & 119.16 & 23.25 & 7.38 & 5646932.52 \\
\hline T & 3 & 25897.97 & 250.34 & 25032.69 & 24195.53 & 23351.22 & 1022.86 & 355.51 & 50.06 & 72212741.76 \\
\hline G×T & 9 & 241.58 & 2.35 & 235.49 & 825.69 & 438.62 & 20.68 & 8.16 & 8.96 & 2192503.82 \\
\hline Error & 48 & 1.02 & 0.01 & 1.00 & 0.79 & 0.67 & 0.03 & 0.01 & 0.01 & 1746.13 \\
\hline C.V (\%) & & 1.58 & 1.58 & 1.69 & 1.60 & 1.53 & 1.57 & 1.81 & 1.97 & 1.74 \\
\hline
\end{tabular}

**=Non-significant, significant at $1 \%$ probability levels, G- Genotypes, T- PEG Levels

Table.2 Mean comparison of main effects of drought stress levels

\begin{tabular}{|c|c|c|c|c|c|c|c|c|c|}
\hline $\begin{array}{c}\text { Drought } \\
\text { stress }\end{array}$ & EP & PI & GSTI & PHSI & RLSI & PR & SR & NSR & SV \\
\hline Control & 100.00 & 10.00 & 99.99 & 100.00 & 100.00 & 20.88 & 11.17 & 4.57 & 5048.79 \\
\hline -2 bars & 82.87 & 7.83 & 78.33 & 70.23 & 63.70 & 13.23 & 5.03 & 1.70 & 2884.43 \\
\hline -4 bars & 70.41 & 6.90 & 69.00 & 40.28 & 32.89 & 6.81 & 2.73 & 2.41 & 1446.39 \\
\hline -6 bars & 7.70 & 0.77 & 7.71 & 9.57 & 12.34 & 2.53 & 0.14 & 0.33 & 79.50 \\
\hline
\end{tabular}

Abbreviations: Emergence percentage (EP) (\%), Promptness Index (PI)(\%), Germination stress tolerance index (GSI)(\%), Plant height stress index (PHSI)(\%), Root length stress index (RLSI) (\%), Primary root length, Number of seminal root, Seminal root length and seed vigour $(\%)$

Table.3 Mean comparison of main effects of maize genotypes

\begin{tabular}{|c|c|c|c|c|c|c|c|c|c|}
\hline $\begin{array}{c}\text { Drought } \\
\text { stress }\end{array}$ & EP & PI & GSTI & PHSI & RLSI & PR & SR & NSR & SV \\
\hline VIM455 & 60.28 & 5.81 & 58.18 & 49.36 & 41.02 & 8.99 & 4.02 & 1.81 & 1978.86 \\
\hline VIM147 & 75.26 & 7.25 & 72.58 & 71.40 & 67.14 & 13.50 & 6.27 & 3.16 & 3045.57 \\
\hline VIM213 & 55.38 & 5.53 & 55.34 & 37.43 & 39.42 & 8.08 & 3.59 & 1.66 & 1768.50 \\
\hline VIM396 & 70.05 & 6.89 & 68.92 & 61.89 & 61.35 & 12.89 & 5.17 & 2.38 & 2666.18 \\
\hline
\end{tabular}


Table.4 Mean performances of maize genotypes under different levels of moisture stress for various plant traits

\begin{tabular}{|c|c|c|c|c|c|c|c|c|c|c|}
\hline GENOTYPES & $\begin{array}{c}\text { PEG } \\
\text { LEVELS }\end{array}$ & $\operatorname{EP}(\%)$ & PI (\%) & GSTI (\%) & PHSI (\%) & RLSI (\%) & PR (\%) & SR (\%) & NSR (\%) & SV (\%) \\
\hline VIM455 & 0 bars & 100 & 10.00 & 100.00 & 100.00 & 100.00 & 21.92 & 11.30 & 5.06 & 4952.00 \\
\hline VIM 147 & 0 bars & 100 & 10.00 & 100.00 & 100.00 & 100.00 & 20.12 & 11.20 & 5.01 & 4962.00 \\
\hline VIM 213 & 0 bars & 100 & 10.00 & 100.00 & 100.00 & 100.00 & 20.50 & 11.09 & 5.02 & 5300.00 \\
\hline VIM 396 & 0 bars & 100 & 10.00 & 100.00 & 100.00 & 100.00 & 21.01 & 11.10 & 5.02 & 4981.00 \\
\hline VIM 455 & -2 bars & 80.08 & 7.12 & 71.20 & 62.68 & 43.48 & 9.53 & 3.11 & 1.27 & 2148.65 \\
\hline VIM 147 & -2 bars & 90.48 & 8.55 & 85.48 & 95.59 & 85.74 & 17.25 & 8.60 & 4.23 & 4112.18 \\
\hline VIM 213 & -2 bars & 70.86 & 6.93 & 69.30 & 29.75 & 45.71 & 9.37 & 2.21 & 1.11 & 1349.19 \\
\hline VIM 396 & -2 bars & 90.21 & 8.75 & 87.49 & 93.06 & 80.01 & 16.81 & 6.21 & 4.11 & 3933.93 \\
\hline VIM 455 & -4 bars & 60.74 & 8.91 & 89.13 & 69.15 & 56.76 & 11.42 & 5.10 & 3.21 & 2883.56 \\
\hline VIM 147 & -4 bars & 90.62 & 5.91 & 59.08 & 33.33 & 19.21 & 4.21 & 1.60 & 0.91 & 814.50 \\
\hline VIM 213 & -4 bars & 50.36 & 4.96 & 49.63 & 19.08 & 10.88 & 2.23 & 1.01 & 0.52 & 424.56 \\
\hline VIM 396 & -4 bars & 79.94 & 7.82 & 78.18 & 39.58 & 44.74 & 9.41 & 3.21 & 3.12 & 1662.84 \\
\hline VIM 455 & -6 bars & 0.33 & 0.25 & 2.48 & 1.45 & 1.41 & 0.31 & 0.09 & 0.02 & 0.23 \\
\hline VIM 147 & -6 bars & 20.11 & 1.59 & 15.88 & 21.02 & 26.19 & 5.27 & 0.22 & 0.21 & 230.64 \\
\hline VIM 213 & -6 bars & 0.33 & 0.25 & 2.48 & 0.92 & 1.12 & 0.23 & 0.08 & 0.01 & 0.17 \\
\hline VIM 396 & -6 bars & 10.07 & 1.01 & 10.05 & 14.93 & 20.66 & 4.34 & 0.17 & 0.11 & 87.00 \\
\hline \multicolumn{2}{|c|}{ Grand Mean } & 65.26 & 6.38 & 63.77 & 55.03 & 52.24 & 10.87 & 4.77 & 2.43 & 2365.15 \\
\hline
\end{tabular}


Fig.1 Standardization of PEG-6000 concentration by petriplate method

a) Drought tolerant genotype

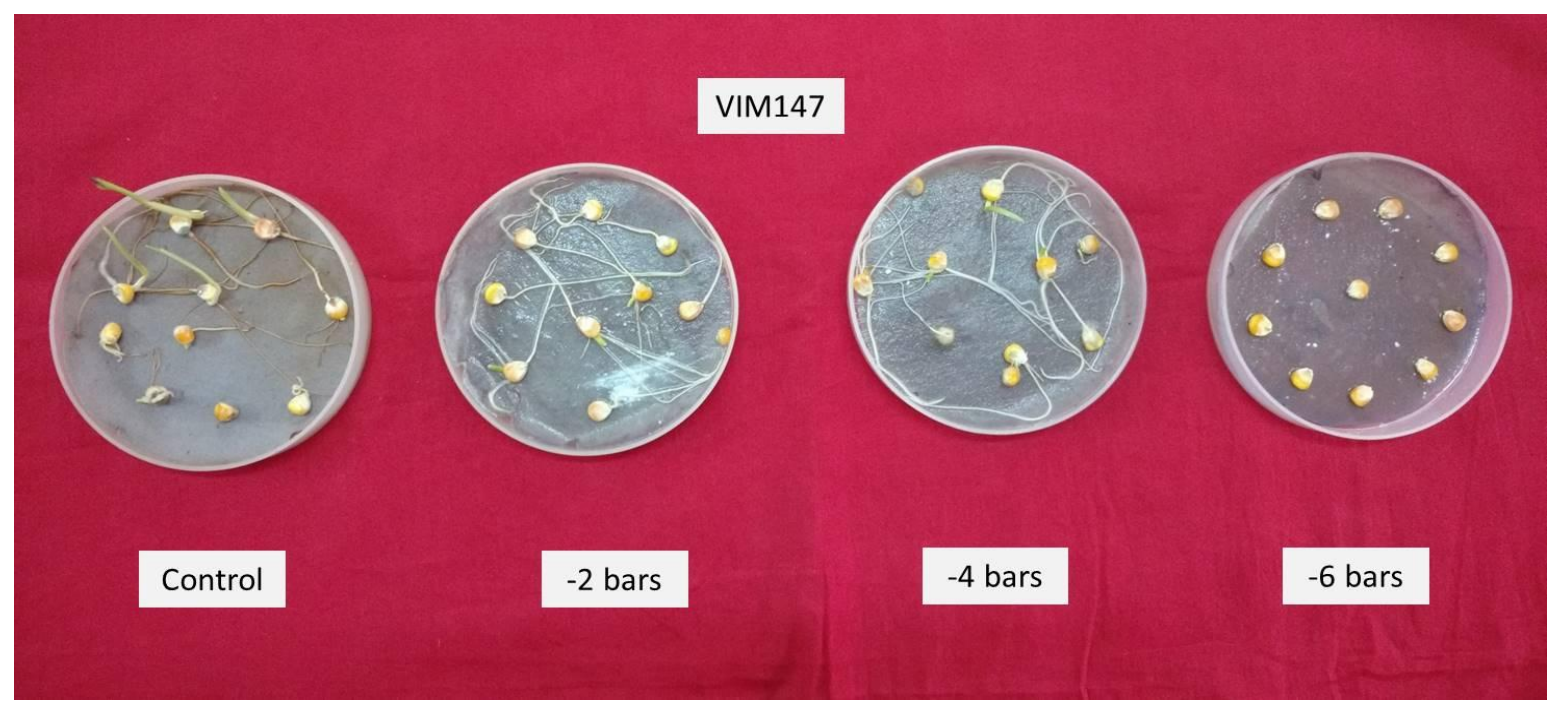

b) Drought sensitive genotype

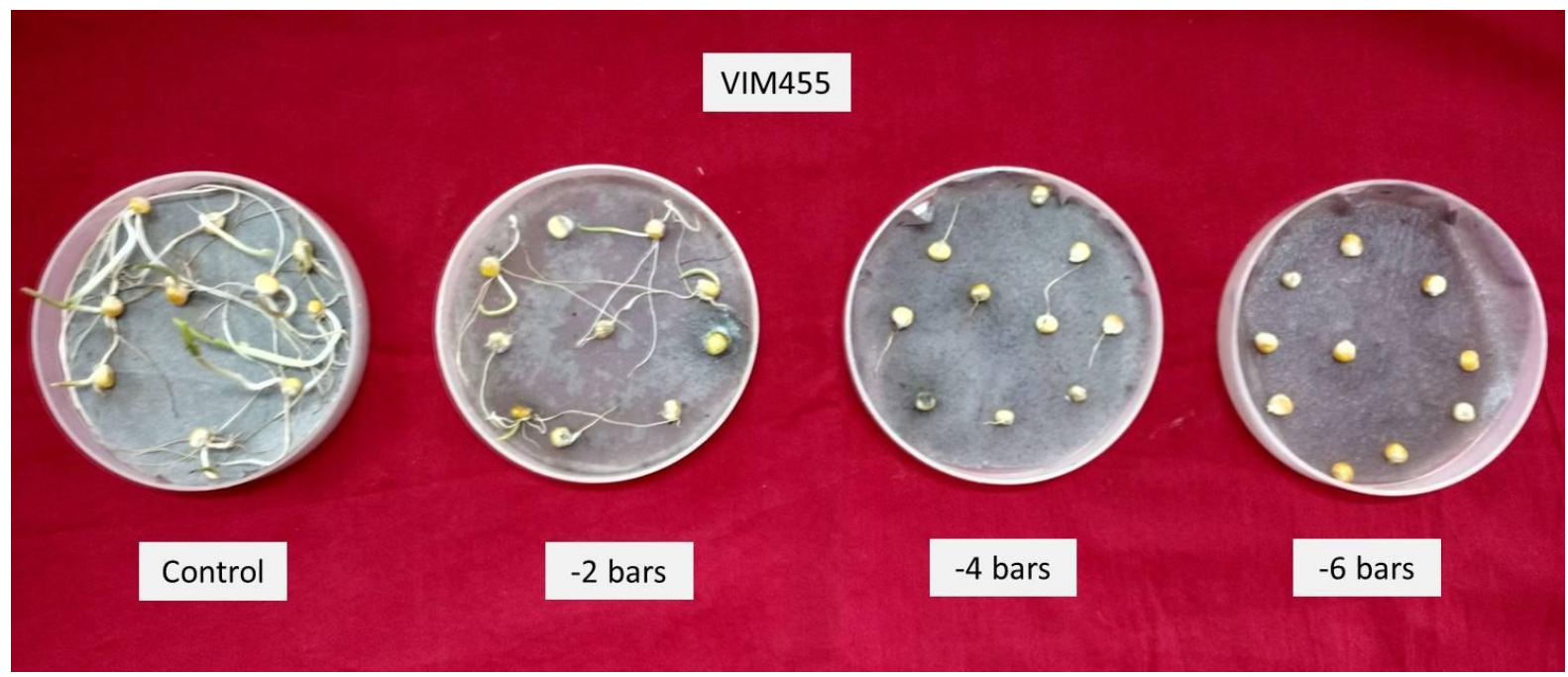


Fig.2 PCA performed on EP, PI, GSTI, PHSI, RLSI, PR, SR, NSR and SV in four maize genotypes under control and water stress

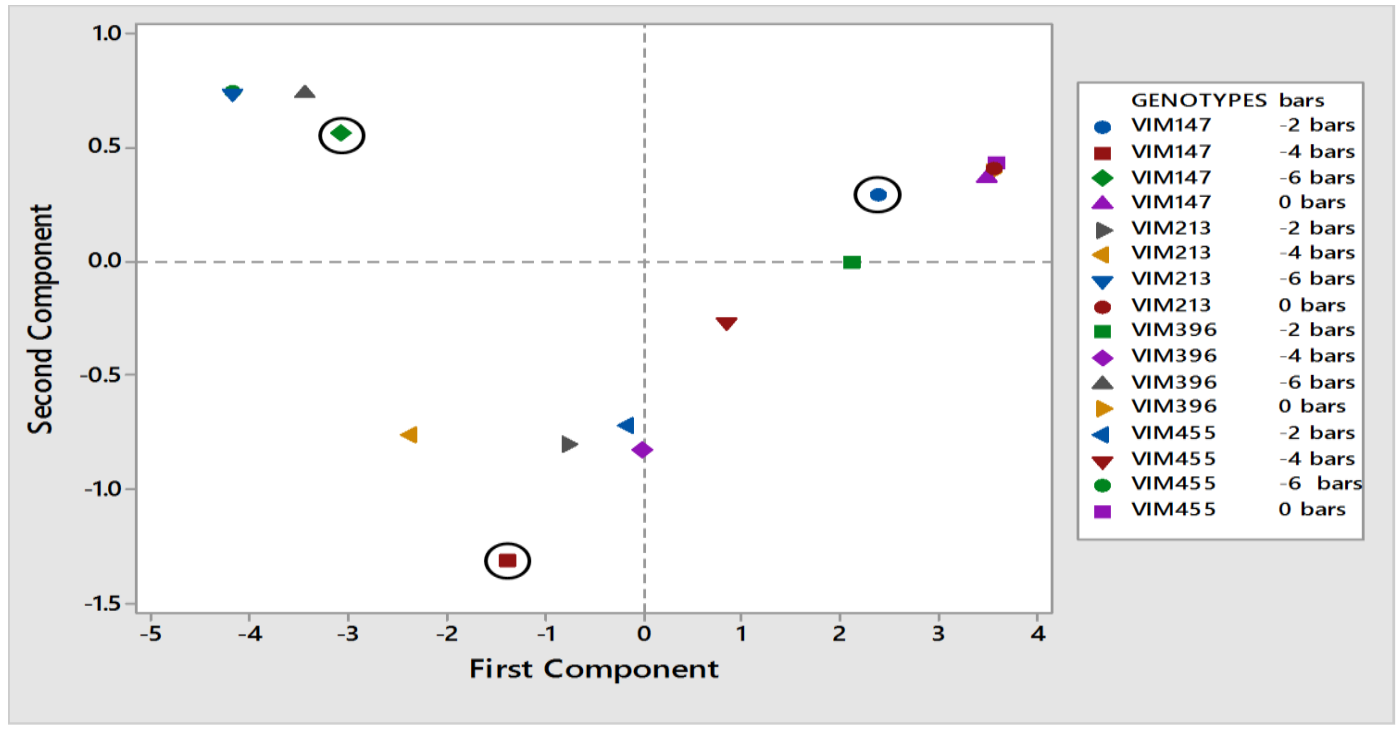

Fig.3 Correlation matrix plot analysis on EP, PI, GSTI, PHSI, RLSI, PR, SR, NSR, SV in four maize genotypes under control and water stress

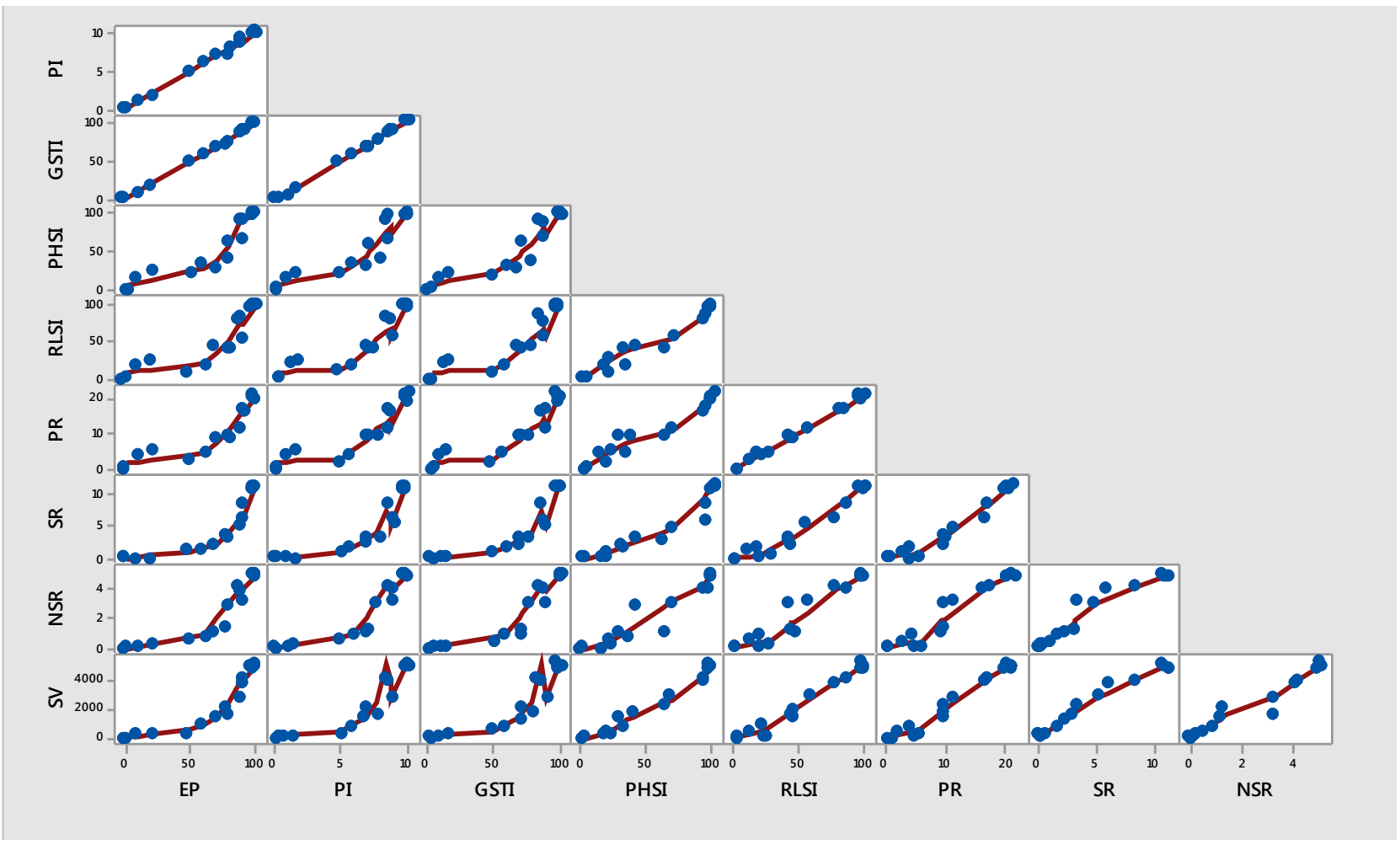


The results exhibited that the genotype VIM147 and VIM396 are water stress tolerant among the genotypes studied, based on the recorded traits and can be further exploited in hybridization programme.

In conclusion, keeping in view the above stated research finding it can be concluded that the two maize genotypes VIM147 and VIM396 performed better under drought conditions and hence can be declared as drought tolerant whileVIM455 and VIM213 genotypes of maize were regarded drought sensitive. Selection can be made on the basis of these characters at early growth stage to screen a large population for drought stress. It would be cost effective, less time consuming and less laborious to screen the germplasm at early growth stage. The study also revealed that variation among genotypes for germination stress tolerance index (GSTI) was found to be a reliable indicator of drought tolerance in maize.

\section{References}

Ahmad, S., R. Ahmad, M.Y., Ashraf, M. Ashraf and Waraich, E.A. 2009. Sunflower (Helianthus annuus L.) response to drought stress at germination and growth stages. Pak. J. Bot., 41: 647-654.

Ashraf, M., and Mehmood, S. 1990. Response of four Brassica species to drought stress. Envir. Expt. Bot., 1: 93-100.

Ayaz, F.A., A.Kadioglu and Urgut, R.T. 2001. Water stress effects on the content of low molecular weight carbohydrates and phenolic acids in Cienanthe setosa. Canadian J. Plant Sci., 80: 373-378.

Bocev, B.V. 1963. Maize selection at an initial phase of development. Kukuruzu, 1: 54 .

Bouslama, M. and Schapaugh, W.T. 1984. Stress tolerance in soybean. Part 1: evaluation of three screening techniques for heat and drought tolerance. Crop Sci. J., 24: 933-937.

Boyer, J.S. 1982. Plant productivity and environment. Sci., 218: 443-448.

Dodd, G.L. and Donovan, L.A. 1999. Water potential and ionic effects on germination and seedling growth of two cold desert shrubs. Am. J. Bot., 86: 1146-1153.

FAOSTAT. 2014. Food and Agricultural Organization of the United Nations (FAO), FAO Statistical Database, 2014, from http: //faostat.fao.org

Farhad, W., M.F. Saleem, M.A., Cheema and Hammad, H. M. 2009. Effect of poultry manure levels on the productivity of spring maize (Zea mays L.). J. Anim. Plant Sci., 19: 122-125.

George, D.W. 1967. High temperature seed dormancy in wheat (Triticum aestivum L.). Crop Sci., 7: 249-253.

Hardegree, S.P., and Emmerich, W.E. 1990. Effect of polyethylene glycol exclusion on the water potential of solutionsaturated filter paper. Plant Physiol., 92: 462-466.

ISTA (International Seed Testing Association). 1996. International rules for seed testing rules. Seed Sci. Technol., 24, Supplement: 155-202.

Khan, A.A., A.R. Sajjad and McNeilly, T. 2004. Assessment of salinity tolerance based upon seedling root growth response functions in maize (Zea mays L.). Euphytica, 131: 81-89.

Khayatnezhad, M., R, Gholamin, S.H., Jamaati - e - Somarin and Zabihi Mahmoodabad, R. 2010. Effects of peg stress on corn cultivars (Zea mays L.) at germination stage. World Appl. Sci. J., 11(5): 504-506.

Khodarahmpour, Z. 2011. Effect of drought stress induced by polyethylene glycol on germination indices in corn (Zea mays L.) hybrids. Afr. J. Biotech., 10(79): 18222-18227. 
Mirza, O.K. 1956. Relationship of radicle development to drought resistance of plants. Indian J. Agron., 1: 41-46.

Mostafavi, K.H., H. Sadeghi Geive, M. Dadresan and Zarabi, M. 2011. Effects of drought stress on germination indices of corn hybrids (Zea mays L.). Int. J. Agri. Sci., 1(2): 10-18.

Rauf, M., M. Munir, M.U. Hassan, M. Ahmad and Afzal, M. 2007. Performance of wheat genotypes under osmotic stress at germination and early seedling growth stage. Afric. J. Biotechnol., 6: 971-975.

Rosegrant, M.W., S. Msangi, C. Ringler, T.B. Sulser, T. Zhu and Cline, S.A. 2008. International Model for Policy Analysis of Agricultural Commodities and Trade (IMPACT): Model Description. International Food Policy Research Institute: Washington, D.C. http: //www.ifpri.org/themes/impact/impactw ater.pdf (accessed May 1, 2011).

Scott, S.J., R.A. Jones and Williams, W.A. 1984. Review of data analysis methods for seed germination. Crop Sci., 24: 1192-1199.

Sidari, M., C. Mallamaci and Muscolo, A. 2008. Drought, salinity and heat differently affect seed germination of Pinus pinea. J. For. Res., 13: 326-330.
Sneath, P.H.A., and Sokal, R.R. 1973. Numerical Taxonomy: The principles and practices of Numerical Classification. W.F. Freeman and Co., San Francisco, pp. 573. Sons, New York, USA.

Steel, R.G.D., J.H. Torrie and Dickey, D.A. 1997. Principles and procedures of statistics. A Biometric Approach. Mc Graw Hill Book Co. New York, USA.

Trida, G.E., S.O.I. Fang-Gong-Suin, B.A. Ping, L.U. Yingyan and Guang-sheng, Z.H. 2006. Effect of water stress on the protective enzymes and lipid per oxidation in radicles and leaves of summer corn. Agric. Sci. China, 5: 228291.

Willanborb, C.J., R.H. Gulden, E.N. Jhonson and Shirtliffe, S.J. 2004. Germination characteristics of polymer-coated canola (Brassica napus L.) seeds subjected to moisture stress at different temperatures. Agron. J., 96: 786-791.

Xiong, L., R. Wang, G. Mao and Koczan J.M. 2006. Identification of drought tolerance determinants by genetic analysis of root response to drought stress and abscisic acid, Plant Physiol., 142: 1065-1074.

\section{How to cite this article:}

Partheeban, C., C.N. Chandrasekhar, P. Jeyakumar, R. Ravikesavan and Gnanam, R. 2017. Effect of PEG Induced Drought Stress on Seed Germination and Seedling Characters of Maize (Zea mays L.) Genotypes. Int.J.Curr.Microbiol.App.Sci. 6(5): 1095-1104. doi: https://doi.org/10.20546/ijcmas.2017.605.119 